\title{
On the Modeling of Carbon Monoxide Flaring in Nigeria
}

\author{
Chrysogonus C. Nwaigwe ${ }^{1}$, Chukwudi J. Ogbonna ${ }^{1} \&$ Ojochekpa Achem ${ }^{1}$ \\ ${ }^{1}$ Department Of Statistics, Federal University Of Technology Owerri, Imo State, Nigeria \\ Correspondence: Chrysogonus C. Nwaigwe, Department Of Statistics, Federal University Of Technology Owerri, Imo \\ State, Nigeria.
}

Received: May 28, 2018 Accepted: July 23, 2018 Online Published: October 15, 2018

doi:10.5539/ijsp.v7n6p94

URL: https://doi.org/10.5539/ijsp.v7n6p94

\begin{abstract}
Data on pollutant emissions in Nigeria were collected across the states to detect any significant change which may cause harm to human health and the environment at large. Three theoretical distributions; Weibull, Log-normal and Gamma distributions were examined on the gas flaring (carbon monoxide) observations to determine the best distribution for the pollutant emissions. The characteristics of the pollutant emissions were obtained and the probabilities of exceeding the Federal Environmental Protection Agency (FEPA) acceptable limits were estimated.
\end{abstract}

Keywords: carbon monoxide, emissions, probability distribution, probability of exceedance

\section{Introduction}

Gas flaring may be defined as the burning and releasing of natural gasses which are associated with crude oil when they are released from the ground. In areas where there is insufficient infrastructure to checkmate gas flaring; gas flaring becomes the only option and thus is employed to dispose of some associated gas. In some chemical factories, oil refineries, oil wells, rings, and landfills, gaseous waste products and sometimes even non-waste gaseous products are routed to elevated vertical chimney and burnt off at its tip. Some gaseous products are subjected to such a process either because the gases are waste or it is difficult to store and transport them. None gaseous wastes are usually burnt off to protect the processing equipment in case of unexpected high pressure within the processing equipment (Evoh,2002). Gas flaring in oil rigs and wells contribute significantly to greenhouse gases in our atmosphere (Ayoola, 2011). It has been said that due to poor infrastructure and unstable practices among oil companies, only about $19 \%$ of the total gas flared may be recovered (Evoh, 2002). It has been observed that, since the discovery of oil in Nigeria in the 1950's, the country has been suffering from the negative environmental consequences of oil development. This is due to the growth of the country's oil industry on one hand and the country's population explosion in conjunction with lack of environmental regulation on the other hand which led to substantial damage to Nigerian environment especially in Niger Delta region, the center of the country's oil industries (Oyekunle, 1999).

Gas flaring from refineries and some other process operations often contain $\mathrm{N}_{2}$ and $\mathrm{CO}_{2}$. No doubt, flaring and venting of associated gases contribute significantly to greenhouse gas (GHG) emissions and has negative impacts on the environment (World bank, 2001), The environmental problems caused by flaring, are global, but to some extent, also regional and local. For example, flaring/venting during oil production operations emits $\mathrm{CO}_{2}$, methane and other forms of gases which contribute to global warming, thereby causing climate change which affects the environmental quality and health of the vicinity of the flares. The health impacts of air pollution have no boundary. Most gas flared contains widely-recognized toxins, such as benzene, which pollute the air. Planning and management as well as the regular monitoring and evaluation of air quality and health impacts are essential if human health and productivity in these countries are to be protected (Faiz and Sturm, 2002).

Beside the effects on the environment, animals, plant life, and human health, gas flaring also has negative impacts on the economics of any nation where it is practiced, in terms of the loss of funds and revenue which could be realized if it had conserved gas instead of flaring it. Ironically, Nigeria is a typical example where such loss is often witnessed.

The problem of carbon monoxide flaring in Nigeria has been in existence for some time now, yet not much has been done to redress the problem, this may be partly due to limited research. More so, not much is known about the distributions of the gaseous emissions. However, understanding the distributions of the emissions will facilitate the understanding of the characteristics and better prediction of their effects to the environment.

Tsokos \& Xu (2009) developed the actual differential equations that characterized the behavior of each of the six variables that constitute the carbon dioxide emissions, namely, gas fuels, liquid fuels, solid fuels, flaring, cement and 
bunker. He obtained a differential equation for each variable that constitutes $\mathrm{CO}_{2}$ emissions and a differential system of the sum of the variables were obtained. Real historical data were used on the subject phenomenon to develop the analytical form of the equations. This model was used to predict $10-50$ year rate of change of the entities that constitute $\mathrm{CO}_{2}$ emissions which may be useful for strategic planning and formulation of policies to mitigate global warming.

Nwaichi (2011) investigated the level and distribution of $\mathrm{CO}_{2}$ and other associated potential contaminants at some flare sites in the Niger Delta to evaluate possible environmental characteristics, two stations, Agbada 1 and 2 of shell petroleum development corporation were monitored while Emeka village with no history of gas flaring was introduced as control for comparison for a period of three months, results showed that the concentrations of $\mathrm{CO}_{2}, \mathrm{CO}$ and associated air pollutants were statistically significant at the choice sites evident in recorded values in comparison to the control site and reference regulatory standard.

Carbon monoxide may be described as a colorless, odorless and highly poisonous gas produced in large quantities as a result of incomplete combustion of fossil fuels. It is known that the main source of carbon monoxide is from motor vehicle exhaust (vehicular emission); about two-third of the pollutant emissions come from transportation sources, while other sources include industrial processes and open burning activities (Eric, Lwanga \& Kanyode, 2004),

The natural concentration of carbon monoxide in air is around $0.2 \mathrm{ppm}$, and that amount is not harmful to humans, while exposure to the pollutant emission at 100ppm or greater can be dangerous to human health (Fellenberg, 2000). Carbon monoxide has the tendency to combine with haemoglobin in the blood. Their combination produces Carboxyl haemoglobin (COHB), thus reducing the capacity of the blood to carry oxygen.

Oguntunde, Odetunmibi and Adejumo (2014) used Gamma, Lognormal and Weibull probability distributions to model period of seven (7) years carbon monoxide emission in Lagos state and they concluded that Gamma distribution best fits the carbon monoxide emissions and that the probabilities of exceeding the Lagos State Environmental Protection Agency (LASEPA) and The Federal Environmental Protection Agency (FEPA) standards are 0.300819 and 0.231621 respectively. Their work was limited to Lagos State. In the present research work, the probability distribution of carbon monoxide flaring across the 36 states of Nigeria for the period of twenty-one (21) years is investigated and the probability that the carbon monoxide emissions would exceed the acceptable limit of its concentration in Nigeria is estimated.

\section{Materials and Methods}

The material studied is the yearly carbon monoxide flared from 1996 to 2016. The area of study is the entire Nigeria. The proposed distributions for studying carbon monoxide emissions in Nigeria alongside the methods of fitting the distributions to the data are hereby discussed. The method of obtaining the probability of exceedance is also discussed in this section.

\subsection{Weibull Distribution}

Let X denote a random variable; a two- parameter Weibull density function is given by Lei. (2008) as;

$$
f(x, \propto, \beta)=\frac{\alpha}{\beta}\left(\frac{x}{\beta}\right)^{\alpha-1} e^{-\left(\frac{x}{\beta}\right)^{\alpha}} ; \quad \propto>0, \beta>0
$$

Where $\alpha$ is the shape parameter and $\beta$ is the scale parameter with mean $\frac{1}{\alpha} \Gamma\left(\frac{1}{\alpha}\right)$ and variance $\Gamma\left(\frac{2}{\alpha}+1\right)-\Gamma^{2}\left(\frac{1}{\alpha}+1\right)$

\subsection{Lognormal Distribution}

A random variable $\mathrm{X}$ is $\log$ normal distributed if $\mathrm{Ln}(\mathrm{X})$ is normally distributed. Its probability density function is given by Brenda (2009) as;

$$
f\left(x ; \mu, \sigma^{2}\right)=\frac{1}{x \sqrt{2 \pi \sigma^{2}}} e^{-\frac{(\ln x-\mu)^{2}}{\sigma^{2}}} ; x>0,-\infty<\mu<\infty, \sigma^{2}>0
$$

Where $\mu$ is the location parameter and $\sigma$ is the scale parameter with mean, $\exp \left(\mu+\frac{\sigma^{2}}{2}\right)$ and variance, $\left[\exp \left(\sigma^{2}\right)-\right.$ 1] $\exp \left(2 \mu+\sigma^{2}\right)$

\subsection{Gamma Distribution}

Let $\mathrm{X}$ denote a random variable. A two parameter gamma density function with parameters $\alpha$ and $\beta$ is given by Forbes, Evans, Hastings, and Peacock, (2011) as;

$$
f(x ; \propto, \beta)=\frac{1}{\Gamma \alpha \beta^{\alpha}} x^{\alpha-1} e^{-\frac{x}{\beta} ;} \quad x>0, \alpha>0, \beta>0
$$

Where $\alpha$ is the shape parameter and $\beta$ is the scale parameter with mean, $\alpha \beta$ and variance, $\alpha \beta^{2}$. 


\subsection{The Test Statistics}

In order to obtain the appropriate model for the carbon monoxide data observations, Anderson - Darling (A-D) tests was used to test for the appropriateness of each selected distribution and the parameters of the distribution were estimated by the maximum likelihood method. The lower the value of each statistic, the closer the fitted distribution appears to match the data. The hypothesis for the test is given as;

$H_{0}$ : The data follow the specified distribution.

$H_{1}$ : The data do not follow the specified distribution.

The test statistic for Anderson-Darling is given by Lu, and Fang (2003) as;

$$
A^{2}=-N-S
$$

Where,

$$
S=\sum_{i=1}^{n} \frac{(2 i-1)}{N}\left[\ln F\left(X_{i}\right)+\ln \left(1-F\left(X_{N+1}-i\right)\right)\right]
$$

$\mathrm{F}$ (.) is the cdf of the continuous distribution, $X_{i}$ is the ordered data and $\mathrm{N}$ is the

Population size.

The adjusted value of Anderson-Darling test for small sample size is,

$$
A D^{*}=A D\left(1+0.75 / n+2.25 / n^{2}\right)
$$

where $A D$ is the calculated value of Anderson-darling test, $n$ is the sample size

\subsection{Probability of Exceedance}

The probability that the carbon monoxide pollutant emission produced by flare event would exceed a specified standard or limit is based on the distribution that best describes the carbon monoxide emissions in Nigeria for the period studied.

The probability of exceeding a critical concentration is given by Yahaya, Ahmad and Ramli, (2008) as,

$$
\operatorname{Pr}(X>x)=1-\operatorname{Pr}(X \leq x)=1-\int_{-\infty}^{x} f(x) d x
$$

\section{Applications}

In this section, data on the emissions of carbon monoxide in Nigeria are presented and summarized, appropriate distribution is fitted to the data and the probability of exceedance is calculated.

Table 3.1. Yearly Carbon Monoxide Emissions in Nigeria (1996 - 2016)

Source: World Data Atlas

\begin{tabular}{l|l}
\hline Year & Value (ton) \\
\hline 1996 & 0.82 \\
\hline 1997 & 0.80 \\
\hline 1998 & 0.70 \\
\hline 1999 & 0.68 \\
\hline 2000 & 0.74 \\
\hline 2001 & 0.77 \\
\hline 2002 & 0.68 \\
\hline 2004 & 0.70 \\
\hline 2005 & 0.66 \\
\hline 2006 & 0.66 \\
\hline 2007 & 0.57 \\
\hline 2008 & 0.51 \\
\hline 2009 & 0.52 \\
\hline 2010 & 0.46 \\
\hline 2011 & 0.50 \\
\hline 2012 & 0.53 \\
\hline 2013 & 0.45 \\
\hline 2014 & 0.48 \\
\hline 2015 & 0.45 \\
\hline 2016 & 0.45 \\
\hline & 0.44 \\
\hline
\end{tabular}




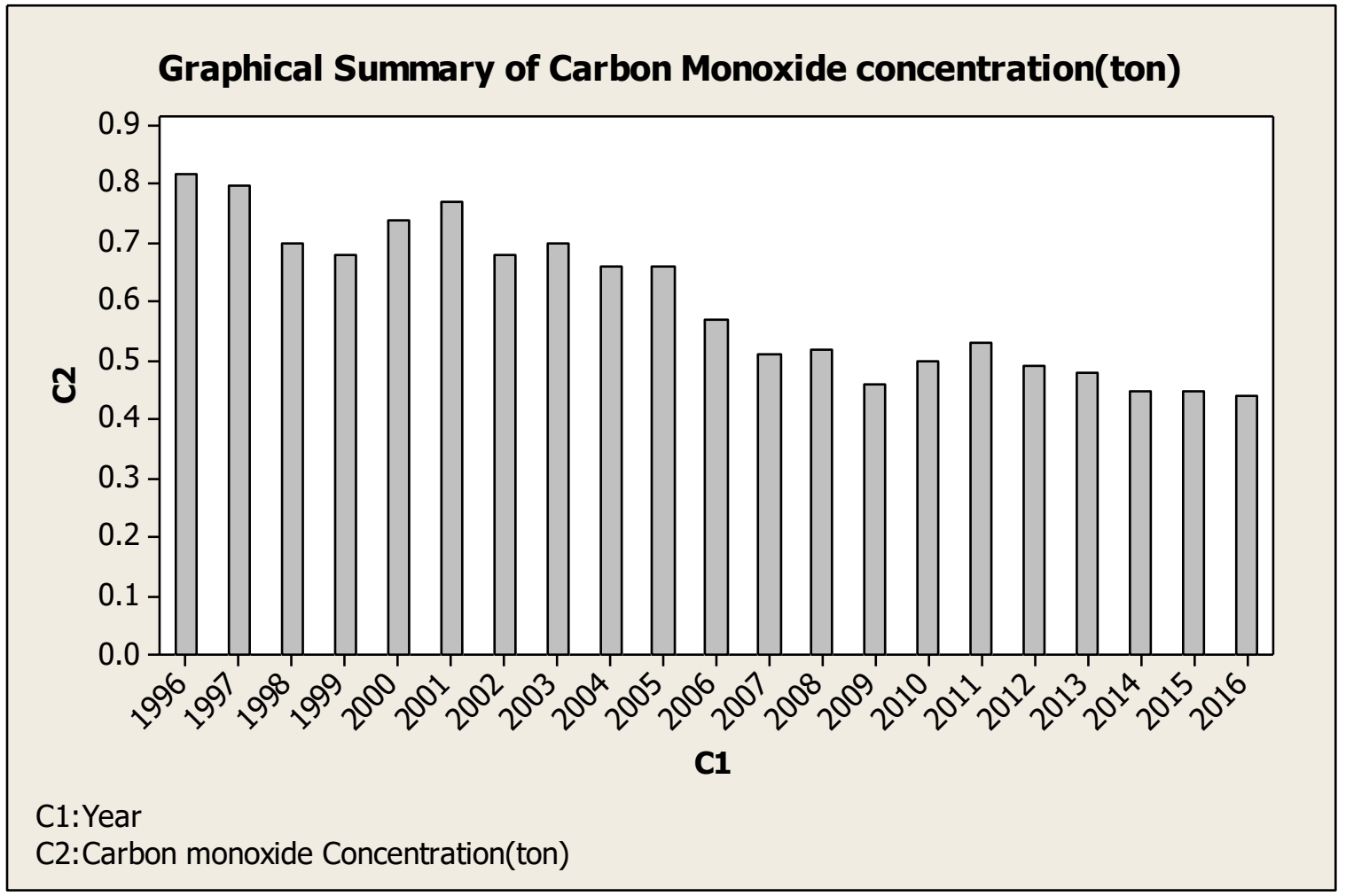

Figure 3.1. Bar Chart of Carbon Monoxide Concentration Data (ton)

It can be deduced from Figure 3.1 that the data on the carbon monoxide emissions are positively skewed and that the mode occurs in 1996 at 0.82 ton. This justifies our choice of positively skewed theoretical distributions to model the data set in this paper. It could also be observed that level of emissions of carbon monoxide decreases progressively from 2011 to 2016. This could be as a result of modern technologies of gas flaring.

\subsection{Fitting of Distributions to the Carbon Monoxide Emissions and Estimation of the Parameters of the Distributions}

In this sub-section, the Gamma, Lognormal and Weibull distributions were fitted to the carbon monoxide emissions in Nigeria and the parameters of the distributions were estimated by the maximum likelihood method..

Table 3.2. Parameter Estimates of the fitted Probability Distributions

\begin{tabular}{l|l}
\hline Distribution & Parameter Estimate \\
\hline Gamma & $\alpha=22.265, \beta=0.02697$ \\
\hline Lognormal & $\sigma=0.20656, \mu=-0.53138$ \\
\hline Weibull & $\alpha=5.0482, \beta=0.64126$ \\
\hline
\end{tabular}

In an attempt to choose the 'best' probability model to describe the carbon monoxide emission data in Nigeria for the period studied, Kolmogorov Smirnov and Anderson-Darling goodness of fit tests were employed in Table 3.3 below

Table 3.3. Results of the Goodness-of-Fit Test

NOTE: * denotes the best fit

\begin{tabular}{l|l|l|l}
\hline Distribution & $\begin{array}{l}\text { Anderson } \\
\text { Darling }\end{array}$ & $\begin{array}{l}\text { Critical Value } \\
\text { for Anderson } \\
\text { Darling }\end{array}$ & $\begin{array}{l}\text { p-value } \\
\text { for } \\
\text { Anderson } \\
\text { Darling }\end{array}$ \\
\hline Gamma & 0.74751 & 1.101 & 0.0434 \\
\hline Lognormal & 0.8143 & 1.101 & 0.0293 \\
\hline Weibull & $0.73311^{*}$ & 1.101 & 0.4409 \\
\hline
\end{tabular}

Comparing the critical value for Anderson Darling test with the calculated value, the results in the table show that, no significant difference was observed between the empirical distribution and each of the theoretical distributions at 0.05 level of significance. The $p$-value for the Weibull distribution in the table (0.4409) shows that $p>0.05$, indicating that there is no significant evidence to reject the null hypothesis that the data follow Weibull distribution. On the other hand, 
the p-values for the Gamma and Lognormal distributions were less than 0.05 , indicating the rejection of the null hypothesis that the distribution of carbon monoxide emissions in Nigeria follows either Gamma or Lognormal distribution. It also shows that the Weibull distribution had the least calculated Anderson Darling value. Therefore, the Weibull distribution was chosen as the most appropriate distribution to describe the emissions of carbon monoxide in Nigeria between 1996 to 2016.

Probability of Exceedance

Since the Weibull distribution best described the data, the probability that the gas flaring concentration would exceed the Federal Environmental Protection Agency (FEPA) standard (10ppm or 0.32ton) is calculated based on the cumulative density function (cdf) of the Weibull distribution. The probability density function of Weibull distribution is given in (2.1)

From Table 2.2, using the scale parameter $\alpha=0.16161$, the location parameter $\beta=0.73311$ with the aid of Microsoft Excel Version 2010, the probability that the carbon monoxide emissions do not exceed the set standard is obtained as, $\operatorname{Pr}(X \leq 0.32)=0.03$.

Hence, the probability that the carbon monoxide emissions would exceed FEPA standard is, $P(X>0.32)=1-0.03=$ 0.97 .

Therefore, the probability that the carbon monoxide emissions exceeded the FEPA standard is 0.97 . This probability is high and therefore indicates that the carbon monoxide emission in Nigeria for the period studied exceeded FEPA standard.

\section{Conclusion}

In this paper, three probability distributions were compared on their appropriateness in describing the carbon monoxide emissions in Nigeria from 1996 to 2016 and the probability of exceeding the set standard was obtained. Descriptive statistics were also used to summarize the data. The results show that the Weibull distribution best described the data and that the probability of exceeding the set standard was very high. Results also show that the emissions decrease in the subsequent years.

\section{Acknowledgement}

We acknowledge the comments of our colleagues in the Department of Statistics, Federal University of Technology Owerri and the authors whose papers improved this article.

\section{References}

Ayoola, T. J. (2011). Gas flaring and its implication for environmental accounting in Nigeria, Journal of sustainable development, 4(5), 244-250

Brenda, F. G (2009). Parameter Estimation for the lognormal distribution. Master's Thesis, Brigham Young University, Provo, United States

Eric, L. K. (2004). Pollutants Emissions Measured. Thesis, Lund University, Sweden.

Evoh, C. (2002). Gas Flares, Oil Companies and Politics in Nigeria, Guardian On-Line-http://ngrguardinannews.com, $18 / 2 / 2002$.

Faiz, A., \& Sturm, P. J. (2002). New directions: air pollution and road traffic in developing countries. Development in Environmental Science, 1, 241-243. https://doi.org/10.1016/S1474-8177(02)80010-9

Fellenberg, G. (2000). The Chemistry of Pollution. England: John Wiley \& Sons Ltd.

Forbes, C., Evans, M., Hastings, N., \& Peacock, B. (2011). Statistical Distributions, $4^{\text {th }}$ edn, Wiley Publishers

Lei, Y. (2008). Evaluation of three methods for estimating the Weibull distribution parameters Chinese Pine .Journal of Forest Science, 54(12), 566-571. https://doi.org/10.17221/68/2008-JFS

Lu, H. C., \& Fang, G. C. (2003). Predicting the Exceedance of a critical $\mathrm{PM}_{10}$ Concentration-A case Study of Taiwan, Atmospheric Environment, 37(4), 3491-3499. https://doi.org/10.1016/S1352-2310(03)00453-9

Nwaichi, S. (2011). Estimation of the carbon monoxide level due to gas flaring in the Niger Delta. Research journal of Environmental science, 5, 565-572. https://doi.org/10.3923/rjes.2011.565.572

Oguntunde, P. E., Odetunmibi, O. A., \& Adejumo, A. O. (2014). A Study of Probability Models in Monitoring Environmental Pollution in Nigeria, Journal of Probability and Statistics, Vol. 2004, Issue 2014.

Oyekunle, L. A. (1999). Gas flaring in Nigeria and environmental pollution control. Proceeding of the $29^{\text {th }}$ Annual Conf. of the NSChE. Port-Harcourt.

Stephens, M. A. (1974). EDF Statistics for goodness of fit and some comparisons. Journal of American Statistical 
Association, 69, 730-737. https://doi.org/10.1080/01621459.1974.10480196

Tsokos, C. P., \& Xu, Y. (2009). Modeling Carbon dioxide emissions with a system of differential equations, Nonlinear Analysis Theory, Methods and Applications, 71(12), 1182-1197.

World Development Report. (2001). Regulation of Associated gas flaring venting. A global overview and lessons from international experience,

Yahaya, A. S., \& Ramli, N. A. (2008). Modeling of Carbon Monoxide Concentration in Major Towns in Malaysia: A Case Study in Penang, Kuching and Kuala Lumpur'. Project Report. University Saints Malaysia.

\section{Copyrights}

Copyright for this article is retained by the author(s), with first publication rights granted to the journal.

This is an open-access article distributed under the terms and conditions of the Creative Commons Attribution license (http://creativecommons.org/licenses/by/4.0/). 